(C) Elsevier/INRA

\title{
Ultrastructural immunolocalisation of histones (H2B, H3, H4), transition protein (TP1) and protamine in rabbit spermatids and spermatozoa nuclei. Relation to condensation of the chromatin
}

\author{
JL Courtens ${ }^{1}$, WS Kistler ${ }^{2}$, L Plöen ${ }^{3}$ \\ 1 INRA, physiologie de la reproduction des mammifères domestiques, 37380 Nouzilly, France; \\ 2 University of South Carolina, Department of Chemistry and Biochemistry, \\ Columbia, SC 29208, USA; \\ ${ }^{3}$ Swedish University of Agricultural Sciences, Department of Anatomy and Histology, \\ 75007 Uppsala, Sweden
}

(Received 7 April 1995; accepted 7 August 1995)

\begin{abstract}
Summary - The histones $\mathrm{H} 2 \mathrm{~B}, \mathrm{H} 3$ and $\mathrm{H} 4$, the transition protein TP1 and protamine were localised using ultrastructural immunocytochemistry in nuclei of rabbit spermatids and spermatozoa. Histones are present in round spermatid nuclei and are lost during the elongation of nuclei. TP1 and protamine appear simultaneously in all nuclei during this period. TP1 is located at the periphery of chromatin cords, while protamine seems to be located at random in the same cords. TP1 is lost in most elongated spermatids during step 13 of spermiogenesis, and the protamine stays in all sperm nuclei. TP1 remains present in some old spermatids and ejaculated spermatozoa. In the rabbit, 3-6\% of sperm nuclei decondense spontaneously. Most are characterised by a retention of TP1. Respective roles of TP1 and the protamine in spermatid nuclear condensation are discussed.
\end{abstract}

rabbit spermiogenesis / spermatozoa / electron microscopical immunocytochemistry / nucleoproteins / chromatin condensation

Résumé - Révélation par immunocytochimie ultrastructurale des histones $\mathrm{H} 2 \mathrm{~B}, \mathrm{H} 3$ et $\mathrm{H} 4$, de la protéine de transition TP1 et de la protamine dans les noyaux des spermatides et des spermatozoïdes de lapin. Leurs rôles dans la condensation de la chromatine. Les histones $H 2 B, H 3$ et $\mathrm{H} 4$, la protéine de transition TP1 et la protamine ont été révélées par immunocytochimie ultrastructurale dans les noyaux des spermatides et spermatozoïdes de lapin. Les histones, présentes dans les noyaux de spermatides rondes, sont perdues au cours de la phase d'allongement des noyaux. TP1 et la protamine apparaissent simultanément dans tous les noyaux pendant cette phase. TP1 est située à la périphérie des cordons de chromatine tandis que la protamine semble localisée au hasard dans ces mêmes cordons. TP1 est perdue dans la plupart des spermatides allongées au cours du stade 13 , tandis que la protamine persiste dans tous les noyaux de spermatozoïdes. TP1 reste toutefois présente dans quelques spermatides âgées et spermatozoïdes éjaculés. Chez le lapin, 3-6\% des 
noyaux de spermatozoïdes se décondensent naturellement. lis sont pour la plupart caractérisés par une rétention de TP1. Les rôles respectifs de TP1 et de la protamine dans la condensation de la chromatine des spermatides sont discutés.

spermiogenèse du lapin / spermatozoïdes / immunocytochimie ultrastructurale / nucléoprotéines / condensation de la chromatine

\section{INTRODUCTION}

Mammalian spermiogenesis is characterised by large modifications in nuclear morphology and chromatin composition. It can be divided into several steps characterised by morphological patterns of the spermatids (Clermont and Leblond, 1955). In the rabbit, 10 different steps have been documented (Plöen, 1971) and sub-types can also be defined from electron-microscopical observations. During these steps, the spherical nuclei of young spermatids become flattened (during the so-called elongation phase). The nucleolus disappears. The chromatin is highly modified in appearance before it condenses to finally form a compact mass. In the mammals studied so far, histones $(\mathrm{H} 1 \mathrm{a}$, $\mathrm{H}$ 1bde, $\mathrm{H} 1 \mathrm{c}, \mathrm{H} 2 \mathrm{~A}$, $\mathrm{X} 2$ (H2A variant), H2B, $\mathrm{H} 3$ and $\mathrm{H}_{4}$ ), present in round spermatids (Baskaran and Rao, 1990; Unni et al, 1994) are replaced by spermatid specific transition proteins $(1-8)$ in elongating spermatids (Loir and Lanneau, 1978), which in turn leave room for the protamine(s) (P1 or $\mathrm{P} 1+\mathrm{P} 2$ ). Not all of these nucleoprotein species are present in all mammals and several precursors for protamines are also described (Chauvière et al, 1992). Rabbit spermatozoa contain only one protamine, which differs slightly from the main mammalian protamine P1 (Ammer and Henschen, 1988). Transition protein 1 and transition protein 2 seem ubiquitous among mammals (Alfonso and Kistler, 1993), while other transition proteins are only present in some species. The compaction of chromatin was first attributed to the formation of a macro-molecular lattice made of protamines and the DNA (Fawcett et al, 1971). However, it is probably a more complicated process since it starts before the protamines enter the spermatid nuclei in many species (Courtens et al, 1983, 1988; Lescoat et al, 1992; Le Lannic et al, 1993), mostly at the time transition nucleoproteins are present (Meistrich et al, 1994). Biochemical studies have shown that transition protein 2 could play a role in condensation of the chromatin (Baskaran and Rao, 1990), while transition protein 1 might be involved in its relaxation (Singh and Rao, 1987; Unni and Meistrich, 1992). Moreover, transition proteins (Akama et al, 1994a) and protamines (Chirat et al, 1991; Green et al, 1994) are phosphorylated/dephosphorylated to different degrees, which hypothetically leads to the final tightness of the chromatin. Rabbit sperm nuclei normally display microheterogeneities in protein/DNA concentrations (Courtens et al, 1991, 1994a) and the condensation of sperm chromatin in the rabbit is also spontaneously reversible in 3-6\% of the cells. A variable proportion of decondensing spermatozoa is found in all ejaculates and is inversely related to litter size (Courtens et al, 1994b).

In the present work, we have focused our attention on the ultrastructural localisation of nucleoproteins in rabbit spermatids, using specific antisera against histones $(\mathrm{H} 2 \mathrm{~B}, \mathrm{H} 3, \mathrm{H} 4)$, transition protein 1 (TP1), the major mammalian protamine (P1), and a specific staining for lysine, an amino acid present in all spermatid nucleoproteins but absent in the protamines (Courtens and Loir, 1981). The first aim of this work was to define the timing of major nucleoprotein changes in normal spermatids. The second was to record eventual nucleoprotein mis- 
composition in naturally decondensing spermatids and spermatozoa. Interestingly, a low proportion of old spermatid and spermatozoa nuclei was decondensed to different degrees and displayed an abnormal TP1 content in all animals.

\section{MATERIALS AND METHODS}

\section{Animals}

A total of 15 adult rabbits were castrated under general anaesthesia; 3 were New Zealand White, and the rest Fauve de Bourgogne. Five ejaculates were obtained using an artificial vagina from Rex rabbits.

\section{Electron microscopy}

Rabbit testes were split into 2 pieces. One was fixed by immersion in $1 \%$ freshly prepared paraformaldehyde in phosphate-buffered saline (PBS), pH 7.4. After $30 \mathrm{~min}$, the testis surface exposed to the fixative was sliced out and cut into smaller pieces about $1 \mathrm{~mm}$ thick, which were allowed to fix for a further $2 \mathrm{~h}$. They were incubated for $30 \mathrm{~min}\left(4^{\circ} \mathrm{C}\right)$ in $0.5 \mathrm{M}$ ammonium chloride in PBS for saturation of free aldehydes from the fixative before being washed for $1 \mathrm{~h}$ in PBS. The second piece of testis was fixed in $4 \%$ glutaraldehyde in PBS for $24 \mathrm{~h}$, followed or not by $1 \%$ osmium tetroxide in PBS for $1 \mathrm{~h}$. Ejaculated spermatozoa were treated the same way, with an additional centrifugation ( $3000 \mathrm{~g}, 10 \mathrm{~min}$ ) after fixation. All samples were dehydrated through an ethyl alcohol series, and were embedded in LR white resin at $4^{\circ} \mathrm{C}$ ( 3 changes $\left.\times 30 \mathrm{~min}\right)$ and in EPON. The blocks were cured at $50^{\circ} \mathrm{C}$ for $2 \mathrm{~d}$, and ultrathin sections were mounted on bare nickel grids.

\section{UItrastructural morphology}

Transmission electron microscopy was performed on ultrathin sections of glutaraldehyde and osmium-fixed material, after staining with uranyl acetate and lead citrate. The stepping of old spermatids is depicted in figure 1 .

\section{Histochemical demonstration of lysine}

Testis samples fixed with glutaraldehyde were stained en masse with $3 \%$ ethanolic phosphotungstic acid for $16 \mathrm{~h}$, according to Courtens and Loir (1981) before being embedded in EPON.

\section{Immunocytochemistry}

\section{Antibodies}

The specificity of the rabbit antisera has been evaluated previously ( $\mathrm{H} 2 \mathrm{~B}, \mathrm{H} 3, \mathrm{H} 4$, Muller et al, 1982a, b, 1985; anti-transition protein 1, Heidaran et al, 1988; anti-protamine, Courtens et al, 1983).

\section{Immunolabelling}

Ultrathin sections of formaldehyde fixed material were floated on drops of $3 \%$ skimmed milk in PBS for $20 \mathrm{~min}$ at room temperature in a humid chamber before the primary antiserum was added at a final concentration 1:500 (anti-protamine, antitransition protein 1, anti H2B) or 1:100 (anti-H3, anti-H4). The humid chamber was left at $4^{\circ} \mathrm{C}$ overnight, and the sections were rinsed thoroughly in PBS, before being incubated in 1:100 biotinylated anti rabbit IgG for $1 \mathrm{~h}$ at $20^{\circ} \mathrm{C}$. After extensive rinses in PBS, they were floated on drops of $1: 20$ streptavidin-gold particles (10 or $13 \mathrm{~nm}$ ) in PBS $\left(20^{\circ} \mathrm{C}\right)$. Controls included the omission of the primary and/or secondary antibodies or the replacement of specific antibodies by preimmune serum when available. The labelled sections were stained with uranyl acetate ( $1 \%, 3 \mathrm{~min})$.

Some sections were double-labelled successively with anti-protamine and anti-transition protein 1 . The primary antibodies were visualised by recombined protein $A / G$ coupled to colloidal gold ( $6 \mathrm{~nm}$ for TP1 and $12 \mathrm{~nm}$ for protamine), following the technique described by Varndell and Polak (1984). The sections, which were first floated over $3 \%$ skimmed milk in PBS for 20 min, were incubated successively with the first primary antiserum $(1: 100,2 \mathrm{~h})$, the first gold probe $(1: 20,30 \mathrm{~min})$, skimmed milk ( $3 \%, 20 \mathrm{~min})$, the second primary 


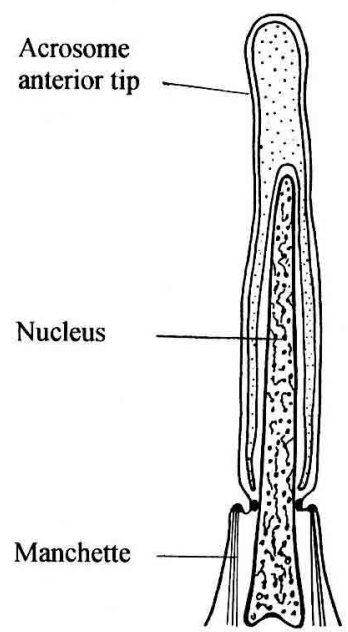

11

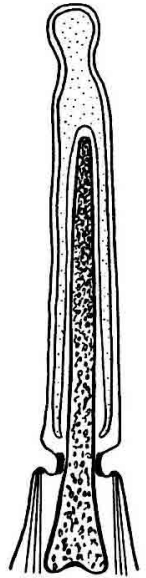

12

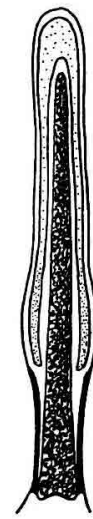

13

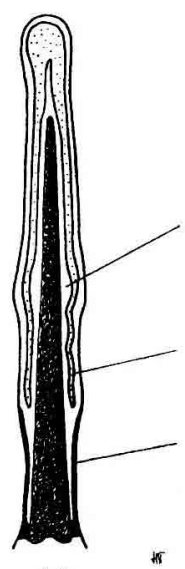

14
Blister of Perinuclear substance

Equatorial segment of the acrosome

Postacrosomal dense lamina

Fig 1. Schematic drawings of spermatids in, from left to right, step 11 (phase G (Plöen, 1971)), early step 12 (phase $\mathrm{H}$ ), the middle of step 13 (phase I) and late step 14 (phase $\mathrm{J}$ ) (close to spermiation) to show structural characteristics of sperm heads. In step 11, the chromatin is organised as longitudinal threads, the acrosome displays a long anterior tip and the manchette is in the equatorial position. In step 12, the chromatin is more condensed in the anterior part of the nucleus than posteriorly, the tip of the acrosome regresses in size, the manchette slides backwards along the nucleus and the postacrosomal dense lamina develops. In step 13, the chromatin is fully condensed, the equatorial segment of the acrosome is thicker than the rest of the acrosomal cap, the manchette has disappeared and the postacrosomal dense lamina is fully developed. In step 14 , the chromatin is condensed, the equatorial segment of the acrosome is thinner than the other acrosomal parts and usually 4 blisters of expanded perinuclear substance are present under the acrosome.

antiserum $(1: 100,2 h)$, and finally with the second gold probe $(1: 20,30 \mathrm{~min})$ at room temperature. Between each incubation, they were washed 6 times in PBS. Controls included the omission of one of the primary antibodies and the inversion of the first/second primary antiserum, for evaluation of binding of the second gold probe to the first antibody. Due to the low contrast of the $6 \mathrm{~nm}$ gold particles, the sections were not post-stained.

\section{RESULTS}

\section{Rabbit-specific morphological data}

In addition to the classical rabbit spermatid morphology, summarised in figure 1 for old spermatids (see also Plöen (1971) for additional steps), numerous nuclei of step 14 spermatids were classified as 'decondensing'. They were characterised by 2 different profiles.

Type 1. The formation of parallel longitudinal fractures appearing in the condensed chromatin, and its separation into threads (fig 2). The fractures were often observed in the posterior part of the nuclei and could lead to the progressive complete decondensation (fig 3 ) of nuclei. Such fractures were also present in $3-6 \%$ of ejaculated spermatozoa nuclei.

Type 2. Few step 13-14 spermatids and testicular spermatozoa had fully decondensed nuclei filled with tiny fibres (see fig 5). 

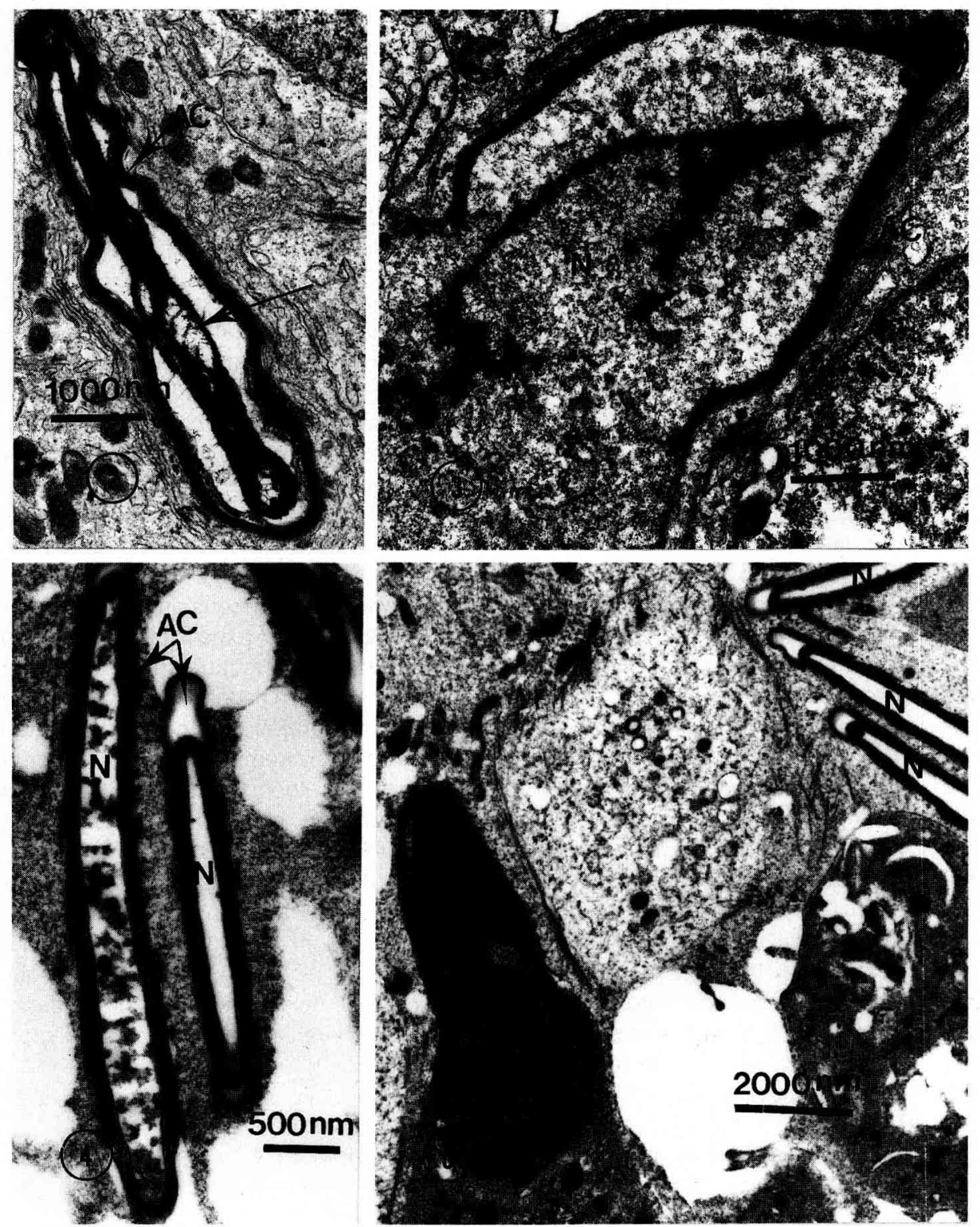

Figs 2-5. All cells have differentiated a thin equatorial segment. They can be classitied as step 14 spermatids. 2. Step 14 spermatid with 'type 1' decondensation. Parts of the chromatin under the equatorial segment of the acrosome are separated in large and thin lamellae (long arrow) ( $A C=$ acrosome). 3. Step 14 spermatid with severe decondensation. The condensed chromatin is only present at the periphery of the nucleus $(N)$. The nuclear envelope is disorganised ( $A C=$ acrosome). 4. Early step 14 spermatids (the posterior part of the equatorial segment of the acrosome is not yet fully thin) stained with ethanolic PTA en masse. The left-hand stained nucleus is still containing lysine, whereas the right-hand one is unstained $(N=$ nucleus, $A C=$ acrosome). 5 . Step 14 spermatids. The nucleus to the left is almost fully decondensed and stained with ethanolic PTA en masse, but the 3 normally condensed nuclei in the top right corner are unstained ( $\mathrm{N}=$ nucleus). 
In addition, some spermatids with the cytoplasmic specialisation specific to step 14 (ie they have differentiated an acrosomal equatorial segment) displayed a chromatin appearance specific of step 11 (see fig 8 ). The frequency of such abnormal spermatids with arrested or delayed nuclear differentiation could be as high as $10 \%$ of the step 14 spermatids in some seminiferous tubules. They were present in all studied animals and in most ejaculates in low proportions $(0.5-1 \%)$.

\section{Histochemical demonstration of lysine}

The chromatin was strongly stained by PTA en masse in all round and elongating spermatids younger than step 12 . At this stage, most of nuclei were partially bleached from the anterior part, posteriorly, with a strict limit between fully condensed, lightly stained anterior chromatin, and thread-like, fully stained, less compact posterior chromatin. The light staining disappeared from the middle of step 13 spermatids and most older nuclei were totally white (figs 4 and 5). However, chromatin remained heavily stained in few step 13 spermatids and in step 14 spermatids displaying nuclear differentiation typical of step 11 (arrested or delayed nuclear differentiation). All the decondensing nuclei observed at step 14 were stained along the fracture lines inside the nuclei. Few nuclei with a classical morphology displayed stained chromatin threads (fig 4). Fully decondensed nuclei were strongly stained (fig 5).

\section{Anti-histones}

For all the anti-histone antibodies, the labelling was intense on heterochromatin of round spermatids and was severely lowered at steps 9-10 (beginning of elongation). It was not found on testicular and ejac- ulated spermatozoa. $\mathrm{H} 3$ and $\mathrm{H} 4$ were only detected in spermatid nuclei from steps 1 throughout 10 , while H2B labelling was lost at step 11.

\section{Anti-transition-protein 1}

Labelling was only present in elongating and elongated spermatid nuclei from steps 10 (fig 6) through the middle of step 13 in all animals. The grains were located close to the external limits of the chromatin threads. The labelling was weak in step 10 and was maximum in step 11-12. At these stages, it leads to a special decoration of nuclei along longitudinal lines, delining more condensed chromatin (fig 7). These lines were about twice as numerous as the final number of longitudinal chromatin plates observed in normal mature testicular spermatozoa (Koehler, 1970). The labelling disappeared from most spermatids in the middle of step 13 , but in many seminiferous tubules, several nuclei at steps 13-15, including those with arrested nuclear differentiation, remained labelled (fig 8 ). In all seminiferous tubules observed at the time of spermiation, several spermatozoa, with no sign of strong nuclear decondensation, were also heavily labelled (fig 9 ). Very few normally compacted nuclei and most of decondensing nuclei were labelled in ejaculated spermatozoa.

\section{Anti-protamine P1}

Labelling was first present in small amounts at the end of step 10 and increased rapidly in step 11 spermatids. At step 10, the few grains were mostly distributed close to the nuclear limits. At step 11 they were present in all parts of nuclei. The maximum grain density was observed on nuclear sections from step 12, 13 and 14 spermatids. Testicular spermatozoa were generally weakly 

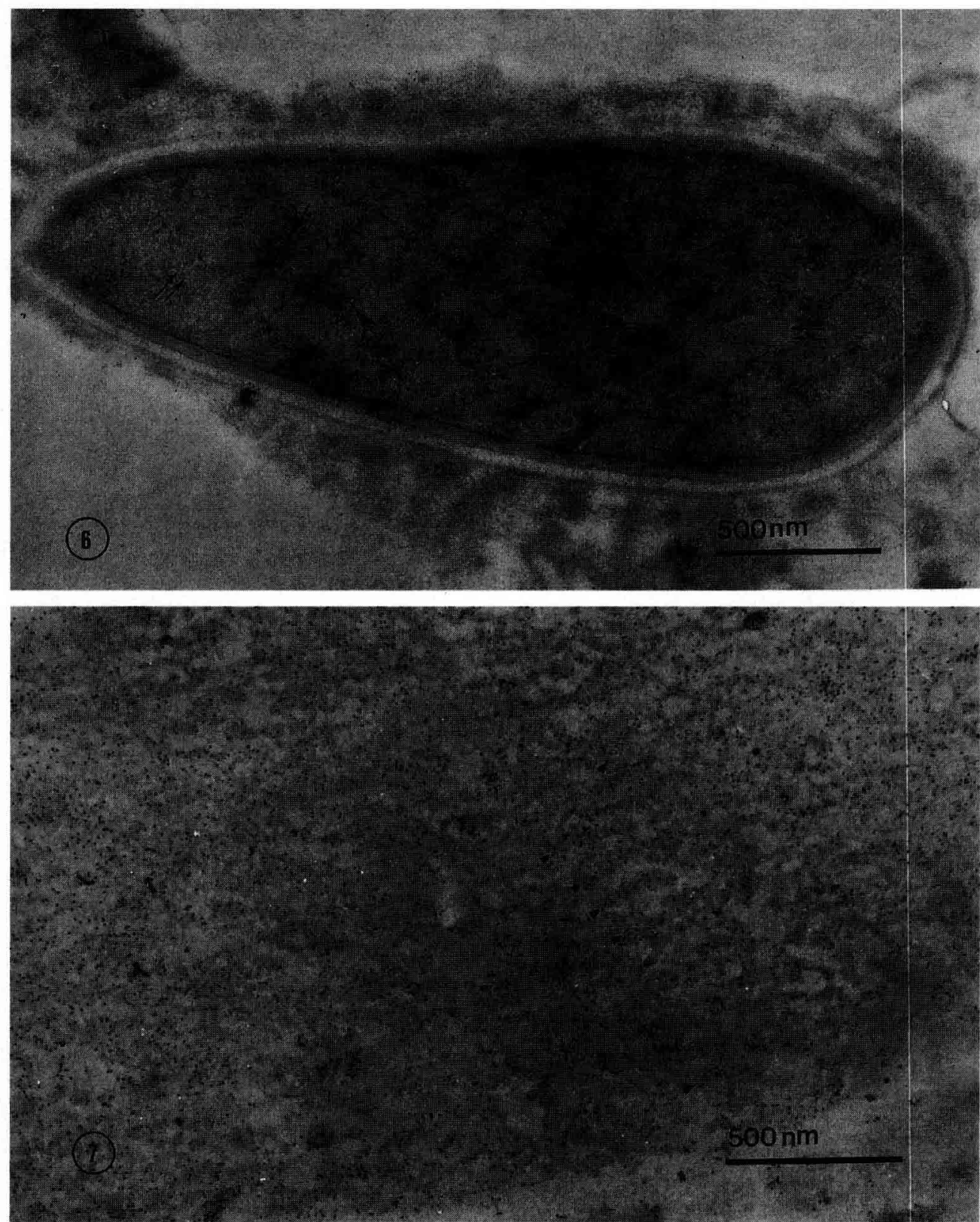

Fig 6. Step 10 spermatid immunostained with anti-TP1-gold. The nucleus contains areas with narrow fibres not labelled (double arrows) and condensing chromatin characterised by larger fibres, which are decorated by the immunolabelling procedure. Few parallel arrays of fibres are present (large arrows).

Fig 7. Step 11 spermatid nucleus immunostained with anti-TP1-gold. Note that the gold particles are located over and mostly close to the periphery of the chromatin threads, which are organised in close to parallel lamellae (arrow heads). 

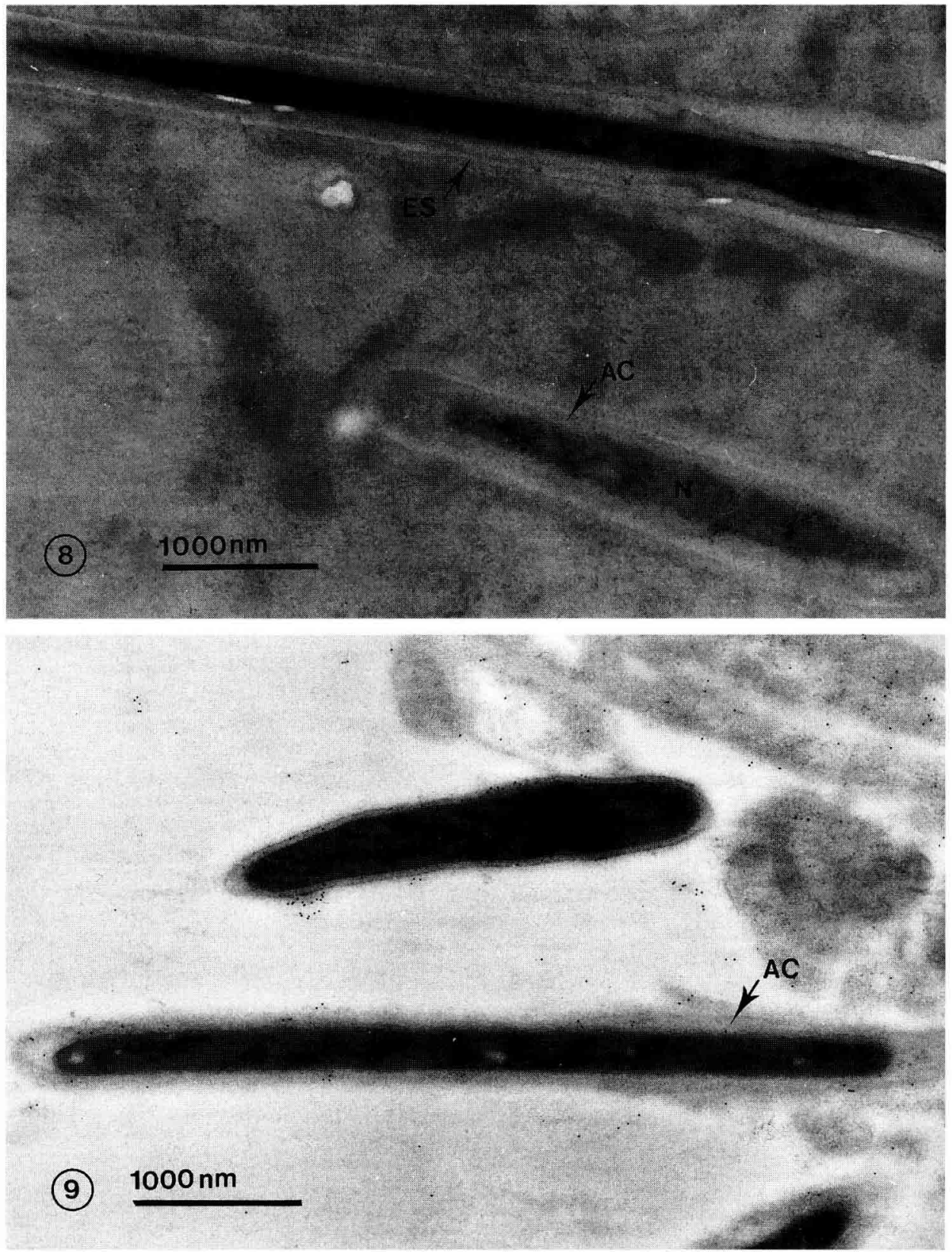

Fig 8. T wo late step 13 anti-TPY-immunoia'beilled spermatid nuciei. Note that the normailly condensed upper nucleus is negative (or not labelled far above background), whereas the lower one, the condensation of which is typical of step 11 spermatids, is positive along longitudinal lines ( $\mathrm{N}=$ nucleus, $\mathrm{AC}=$ acrosomal cap, $\mathrm{ES}=$ equatorial segment of the acrosome).

Fig 9. Two testicular spermatozoa (at spermiation). The lower nucleus is normally condensed and unstained (the few grains present can be considered as background). The upper one which is slightly decondensed, shows intense immunostaining with anti-TP1 $(\mathrm{N}=$ nucleus, $\mathrm{AC}=$ acrosome). 
labelled, probably due to higher chromatin compaction and reduced access to the epitopes.

\section{Double labelling against TP1 and protamine}

This double labelling was weaker over spermatid nuclei than the single labelling described above. This could be due to the one-step technique used to visualise each of the primary antibody/epitope locations. The distribution of grains was similar to that described above, for a given cell stage, and for a given antiserum, whatever the order for (and or deletion of) the first primary antiserum. Small grains over TP1 and large grains over protamine locations did not overlap, whatever the cell differentiation, suggesting that both nucleoproteins could have separate locations over the chromatin (figs 10 and 11). However, the weak labelling, and the lack of post-staining of the sections could not demonstrate clearly the specific location of TP1 over the threads of chromatin. Several step 14 spermatids with fully decondensed nuclei were not labelled at all, as if both protamine and TP1 had been lost.

\section{DISCUSSION}

In the present work, we have shown that: i) histones are lost in elongating spermatids, $\mathrm{H} 2 \mathrm{~B}$ being lost later (step 11) than $\mathrm{H} 3$ and H4 (step 10); ii) TP1 and protamine appear together in step 10-11 spermatids; TP1 is located mostly at the periphery of chromatin threads; iii) TP1 is present in fully condensed nuclei at the middle of step 13 and is not detected by immunocytochemistry in most normal step 14 spermatids and testicular spermatozoa; and iv) most of decondensing spermatid and spermatozoon nuclei were stained for lysine and were labelled for TP1 along fracture lines separating chro- matin lamellae while few old spermatids and spermatozoa with normal morphology were labelled nuclei.

Histones are lost in elongating spermatids, H2B being lost later (step 11) than $\mathrm{H} 3$ and $\mathrm{H} 4$ (step 10). This is a confirmation of results obtained in the mouse (Biggiogera et al, 1992) and the rat (Unni et al, 1994). The sum of labelling for all histones was quite low at step 10, when TP1 and protamine are not yet present in large amounts. This suggests that TP1 and protamine, which enter the nuclei when most of core histones have disappeared, could not facilitate the displacement of $\mathrm{H} 3$ and $\mathrm{H} 4$ as postulated by Unni and Meistrich (1992). The displacement of histones by more basic nucleoproteins is also questionable in humans, since the persistence of histones in many spermatozoa could be a rule, as demonstrated by biochemistry (Gatewood et al, 1990), staining with en masse alcoholic phosphotungstate (Baccetti et al, 1977) or aniline blue (Haidl and Schill, 1994). The present results also suggest that some other nucleoproteins should be present in spermatid nuclei at the beginning of nuclear elongation. These could include testis specific histones variants (Unni et al, 1994) and/or transition protein 2 (Alfonso and Kistler, 1993) an in vitro DNA-stabilising protein (Baskaran and Rao, 1990). Another possible explanation for the poor histone immunolocalisation in step 10 spermatids could be the modification of the protein conformation and the access to antibodies due to histone acetylation. This was not tested in the present work.

TP1 and protamine do appear together in step 10-11 spermatids. This is a new observation in mammals, since transition proteins were formerly supposed to be present only before the first appearance of protamine in nuclei. In the rabbit, TP1 appears in young step 10 nuclei, while protamine 1 is only present close to the nuclear envelope by the end of step 10 and fills the other nuclear 

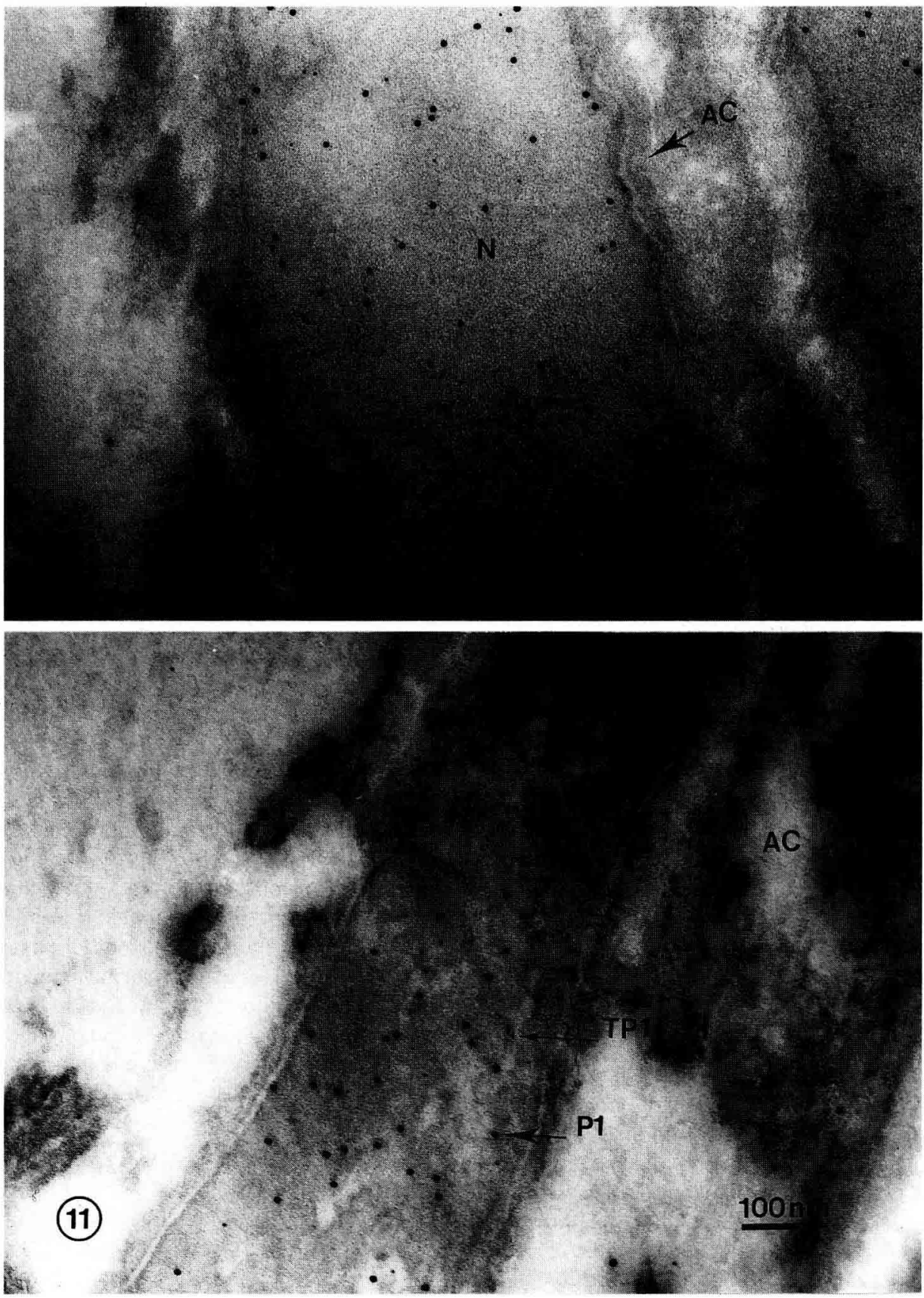

Figs 10-11. Step 11 spermatid (10) and step 12 (11) equatorial part of the cells; double immunolabelling. The small gold particles correspond to anti-TP1, and the larger particles to antiprotamine. Note that the particles are found over different areas of the nucleus $(N)$. The ratio of TP1/P1 grains is close to a half in both images $(\mathrm{N}=$ nucleus, $A C=$ acrosome $)$. 
areas during step 11. They remain present in separate locations over the chromatin threads, TP1 being mostly located at their periphery and possibly delineating the future chromatin lamellae of sperm nuclei. The presence of small amounts of protamine in early elongating spermatids (late step 10) has not been documented in other mammalian species. Using our antisera, it was demonstrated that protamine only appears at step 12 in the ram (Courtens et al, 1983), and is present in low amounts, close to the nuclear envelope, at step 11 in the boar (Courtens et al, 1988). The fact that small amounts of protamine could be first detected during step 10, together with TP1 in the present work is probably not artifactual, since both antisera reveal each one band on Western blots of rabbit testis extracts (not shown). Moreover, the separate locations of protamine and TP1 on the same threads of compacting chromatin suggest that both proteins could cooperate in the rearrangements of chromatin which occur during nuclear elongation. In vitro, TP1 induces a pronounced equilibrium destabilisation of the DNA (Singh and Rao, 1987). In vivo, protamine can fix the chromatin structure, whatever the step at which it is introduced to nuclei and whatever the previous local arrangement of chromatin (Courtens, 1982; Biggiogera et al, 1992). The fact that TP1 is located at the periphery of threads, and seems to remain in that place, forming longitudinal decorations in older spermatids, may indicate that it is involved in the formation of the chromatin plates which are present in old spermatids and spermatozoa (Koehler, 1970; Courtens et al, 1991), or could at least facilitate their further separation in the nuclei that undergo decondensation. This is documented by the fact that TP1 remains present at the site of separation of lamellae in most spermatids and spermatozoa nuclei which decondense spontaneously (present cytochemical and immunocytochemical demonstration). If it can be argued that lysine-containing pro- teins could have entered the nuclei after decondensation, when the nuclear envelope has been disrupted, it is clear that TP1 remains present in few nuclei with normal morphology and intact nuclear envelope. Its presence could then reveal cell nuclei which have not yet started to decondense. Protamine, on the other hand, could be involved in the internal compaction of the threads.

TP1 is not detected by immunocytochemistry in most step 14 spermatids and testicular spermatozoa but is present in wellcondensed nuclei at the middle of step 13. This raises the question of how it is eliminated, meaning separation from the DNA and release from the dense chromatin. Separation of TP1 from the DNA is probably not due to displacement by protamine as postulated by Green et al (1994), because both nucleoproteins are present together in nuclei for several days during rabbit spermiogenesis and because their immunolocalisations do not overlap. This is also obvious from the chronology of step-specific immunolocalisation of TP1 in the mouse and the rat (Heidaran et al, 1988). Separation of TP1 from DNA should be facilitated by its phosphorylation as proposed in the boar (Akama et al, 1994a). Phosphorylation sites are also present in ram TP1 (Chirat et al, 1991). However the release of DNA-detached transition proteins from the nuclei could be a problem in compact nuclei. They could either follow the paths left free between the condensed plates of chromatin or be degraded. They could also be simply trapped in few condensed nuclei. The recent proposal that a protease could be involved in the degradation of transition proteins is interesting, even if the origin of enzymes (acrosomal or nuclear) is not documented from in vitro experiments (Akama et al, 1994b). Hypothetical intranuclear protease activity, such as that found in the mouse (Faulkner and Bhatnagar, 1987), could explain why several fully decondensed rabbit spermatid 
nuclei lack both immunodetectable protamine and TP1. Could proteases enter the nuclei of old spermatids, as do protein disulfide isomerase (Ohtani et al, 1993), or be already present as oligoproteins as proposed for centromere proteins in bull (Palmer et al, 1990) and rabbit (Courtens et al, 1992) spermatozoa? On the other hand, the lack of elimination of TP1 in several cells could explain the spontaneous decondensation of nuclei which occurs frequently in step 14 spermatids (present work) and in spermatozoa of the rabbit (Courtens et al, 1994b). The separations between chromatin lamellae, can be both delineated by lysine staining (alcoholic phosphotungstate) and immuno-localisation of TP1 (a lysine-rich protein: Heidaran et al, 1988). TP1, which remains localised at the periphery of the chromatin lamellae, could inhibit or lower their mutual cohesiveness, and leads to more fragile nuclei. TP1 is probably not the only nucleoprotein to be left is some sperm nuclei. Transition protein 4 has been found as traces in few boar late spermatids (Akama et al, 1994b) and rat epididymal spermatozoa (Unni and Meistrich, 1992). Histones are present in human spermatozoa (Gatewood et al, 1990). The state of protamines phosphorylation (Chirat et al, 1993), or the underprotamination of the chromatin (Bianchi et al, 1994) could also explain poor chromatin condensation in several sperm nuclei. The lack of one protamine species is also documented in human (De Yebra et al, 1993). In the rabbit, chromatin micro-heterogeneities, characterised by easily extractable protamine, have been described in spermatozoa as sites where the DNA is more accessible (Courtens et al, 1994a). However, in this species, the frequency of sperm nuclei which spontaneously decondense is the main factor related to low litter sizes (Courtens et al, $1994 b$ ), one of the main parameters of fertility. The present results, showing that several type of nuclear decondensation are characterised by the abnormal retention of
TP1, should therefore be considered when rabbit fertility is investigated. Moreover, they suggest that TP1 is involved in the lamellar superorganisation of the sperm nuclei and that its release from spermatid nuclei is probably not a simple displacement by protamines.

\section{ACKNOWLEDGMENTS}

This work was started during a stay of LP at INRA. It was funded by INRA-DRI, INRA-AIP Interactions Intragonadiques and the Swedish Council for Forestry and Agricultural Research. Antibodies against histones were gifts from S Muller (Strasbourg, France). Rabbit ejaculates were obtained from INRA, Centre de recherches du Magneraud (Dr Thébault). Dark room work by $M$ Ekwall and drawings by $\mathrm{H}$ Tylza are acknowledged.

\section{REFERENCES}

Akama K, Kojima S, Nakano M, Tobita T, Hayashi H (1994a) The amino acid sequence and phosphorylation sites of a boar transition protein 1. Biochem Mol Biol int 32, 349-357

Akama $\mathrm{K}$, Ichimura $\mathrm{H}$, Kosuge $\mathrm{M}$ et al (1994b) Isolation of intact transition protein 4 from boar late spermatid nuclei. Biochem Mol Biol Int 34, 315-321

Alfonso PJ, Kistler WS (1993) Immunohistochemical localization of spermatid nuclear transition protein 2 in the testes of rat and mice. Biol Reprod 48, 522529

Ammer $\mathrm{H}$, Henschen A (1988) Primary structure of rabbit sperm protamine, the first protamine of its type with an aberrant $\mathrm{N}$-terminal. FEBS Lett 242, 111 116

Baccetti B, Renieri T, Rosati F, Selmi MG, Casanova S (1977) Further observations on the morphogenesis of the round-headed human spermatozoa. Andrologia 9, 255-264

Baskaran R, Rao MRS (1990) Interaction of spermatid specific protein TP2 with nucleic acids, in vitro. A comparative study with TP1. J Biol Chem 265 , 21039-21047

Bianchi PG, Manicardi GC, Pantano S et al (1994) Underprotamination and nicking of DNA in ejaculated human spermatozoa are highly related phenomena. In: Seventh International Symposium on Spermatology, Cairns North Queensland, Australia (M Bradley, J Cummins, eds), p 7.4 
Biggiogera M, Muller S, Courtens JL, Fakan S, Manfredi-Romanini G (1992) Immunoelectron microscopical distribution of histones $\mathrm{H} 2 \mathrm{~B}$ and $\mathrm{H} 3$ and protamine in the course of mouse spermiogenesis. $J$ Elect Microsc Tech 20, 259-267

Chauvière $M$, Martinage $A$, Debarle $M$, Sautière $P$, Chevaillier $P$ (1992) Molecular characterization of six intermediate proteins in the processing of mouse protamine precursor. Eur J Biochem 204, 759-765

Chirat F, Martinage A, Brian G et al (1991) Nuclear transition protein 1 from ram elongating spermatids. Mass spectrophotometric characterization, primary structure and phosphorylation sites of two variants. Eur J Biochem 198, 13-20

Chirat $F$, Arkhis A, Martinage A, Jaquinod $M$, Chevaillier $P$, Sautière $P(1993)$ Phosphorylation of human sperm protamines HP1 and HP2: identification of phosphorylation sites. Biochim Biophys Acta 1203, 109-114

Clermont $Y$, Leblond CP (1955) Spermiogenesis of man, monkey, ram and other mammals as shown by the 'periodic acid Schiff' techniques. Am J Anat 96, 229. 253

Courtens JL (1982) Rôles indirects des microtubules dans la morphogenèse nucléaire des spermatides. Reprod Nutr Dev 22, 825-840

Courtens JL, Loir M (1981) Ultrastructural detection of basic nucleoproteins. Alcoholic phosphotungstic acid does not bind to arginine residues. $J$ Uitrastruct Res $74,322-326$

Courtens JL, Delaleu B, Dubois M, Lanneau M, Loir M, Rozinek J (1983) Immunocytochemical localization of protamine in the spermatids of the ram. Gamete Res 8, 21-28

Courtens JL, Plöen L, Loir M (1988) Immunocytochemical localization of protamine in the boar testis. $J$ Reprod Fert 82, 634-643

Courtens JL, Biggiogera M, Fakan S (1991) A cytochemical and immunocytochemical study of DNA distribution in spermatid nuclei of mouse, rabbit and bull. Cell Tiss Res 265, 517-525

Courtens JL, Biggiogera M, Rothfield N, Burnier M, Fakan S (1992) Migration of centromere proteins in rabbit spermiogenesis. Mol Rep Dev 32, 369-377

Courtens JL, Biggiogera M, Fakan S (1994a) Distribution of DNA, nuclear microheterogeneities and compaction of the chromatin in rabbit epididymal spermatozoa. Ultrastructural evaluation of the Feulgenlike technique using osmium ammine. Reprod Nutr Dev 34, 261-272

Courtens JL, Bolet G, Theau-Clément M (1994b) Effect of acrosome defects and sperm chromatin decondensation on fertility and litter size in the rabbit. Preliminary electron-microscopic study. Reprod Nutr Dev 34, 427-437

De Yebra L, Ballescà JL, Vanrell JA, Bassas L, Oliva R (1993) Complete selective absence of protamine P2 in humans. J Biol Chem 268, 10553-10557
Faulkner RD, Bhatnagar YM (1987) A protease activity is associated with testicular chromatin of the mouse. Biol Reprod 36, 471-480

Fawcett DW, Winston AA, Phillips DM (1971) Morphogenetic factors influencing the shape of the sperm head. Dev Biol 26, 220-251

Gatewood JM, Cook GR, Balhorn R, Schmid CW, Bradbury EM (1990) Isolation of 4 core histones from human sperm chromatin representing a minor subset of somatic histones. J Biol Chem 265, 20662-20666

Green GR, Balhorn R, Poccia DL, Hecht NB (1994) Synthesis and processing of mammalian protamines and transition proteins. Mol Reprod Dev 37, 255263

Haidl G, Schill WB (1994) Assessment of sperm chromatin condensation: an important test for prediction of IVF outcome. Arch Androl 32, 263-266

Heidaran MA, Showman RM, Kistler WS (1988) A cytochemical study of the transcriptional and translational regulation of nuclear transition protein 1 (TP1), a major chromosomal protein of mammalian spermatids. J Cell Biol 106, 1427-1433

Koehler JK (1970) A freeze-etching study of rabbit spermatozoa with particular reference to head structures. $J$ Ultrastruc Res 33, 598-614

Le Lannic G, Arkhis A, Vendrely E, Chevaillier P, Dadoune JP (1993) Production, characterization, and immunocytochemical application of monoclonal antibodies to human sperm protamines. Mol Reprod Develop 36, 106-112

Lescoat D, Blanchard $Y$, Lavault MT, Quernée $D$, Le Lannou D (1992) Ultrastructural and immunocytochernical study of $P 1$ protamine localization in human testis. Andrologia 25, 93-99

Loir M, Lanneau M (1978) Partial characterization of ram spermatidal basic nucleoproteins. Biochem Biophys Res Comm 80, 975-982

Meistrich ML, Trostle-Weige PK, van Beck MEAB (1994) Separation of specific stages of spermatids from vitamin A-synchronized rat testes for assessment of nucleoprotein changes during spermiogenesis. Biol Reprod 51, 334-344

Muller S, Erard M, Burggraf E et al (1982a) Immunocytochemical detection of changes in chromatin subunits induced by $\mathrm{H} 4$ acetylation. EMBO J 1, 939-944

Muller S, Himmelspach K, Van Regenmortel MHV (1982b) Immunocytochemical localization of the Cterminal hexapeptide of histone $\mathrm{H} 3$ at the surface of chromatin subunits. EMBO J1, 421-425

Muller S, Couppez M, Brian JP, Gordon J, Sautière P, Van Regenmortel MHV (1985) Antigenic structure of histone H2B. Biochim Biophys Acta 827, 235-246

Ohtani $\mathrm{H}$, Wakui $\mathrm{H}$, Ishino $\mathrm{T}$, Komatsuda $\mathrm{A}$, Miura AB (1993) An isoform of protein disulfide isomerase is expressed in the developing acrosome of spermatids during rat spermiogenesis and is transported into 
the nucleus of mature spermatids and epididymal spermatozoa. Histochemistry 100, 423-429

Palmer DK, O'Day K, Margolis RL (1990) The centromere specific histone CENP-A is selectively retained in discrete foci in mammalian sperm nuclei. Chromosoma 100, 32-36

Plöen $L$ (1971) A scheme of rabbit spermatoleosis based upon electron microscopical observation. Z Zellforsch 115, 553-564

Singh J, Rao MRS (1987) Interaction of rat testis protein, TP, with nucleic acids in vitro. J Biol Chem 262 , 734-740
Unni E, Meistrich ML (1992) Purification and characterization of the rat spermatid basic nuclear protein TP4. J Biol Chem 267, 25359-25363

Unni E, Zhang Y, Kangasniemi M, Saperstein W, Moss SB, Meistrich ML (1994) Specific histones in rat spermatids. In: Seventh International Symposium on Spermatology, Cairn, North Queensland, Australia (M Bradley, J Cummins, eds), p 2.12

Varndell IM, Polak JM (eds) (1984) Double immunostaining procedure: Techniques and applications. In: Immunolabelling for Electron Microscopy, Elsevier Science Publishers, Amsterdam 